\title{
DESAIN TEKNIS PELEDAKAN BATU KAPUR UNTUK MEREDUKSI EFEK GETARAN TANAH
}

\section{TECHNICAL DESIGN OF LIMESTONE BLASTING TO REDUCE THE EFFECT OF GROUND VIBRATION}

\author{
Bochori $^{1}$, A. Suherman ${ }^{2}$, D. Purbasari ${ }^{3}$ \\ ${ }^{1-3}$ Jurusan Teknik Pertambangan Fakultas Teknik Universitas Sriwijaya \\ Jl. Raya Palembang-Prabumulih Km. 32 Indralaya 30662 \\ e-mail: Bochori@ft.unsri.ac.id
}

\section{ABSTRAK}

\begin{abstract}
Kegiatan peledakan di PT Semen Baturaja (Persero), Tbk., menggunakan bahan peledak Dabex dan penyalaan dengan non electric detonator (nonel). Permasalahan muncul karena lokasi peledakan relatif dekat dari lokasi pemukiman sehingga sering kali ada keluhan dari masyarakat terhadap getaran peledakan. Oleh karena itu, dampak getaran tanah merupakan salah satu fokus perhatian dari operasi penambangan pada perusahaan ini. Penelitian yang dilaksanakan bertujuan untuk meminimalisir dampak getaran tanah agar dapat memenuhi baku tingkat getaran berdasarkan SNI 7571 : 2010. Penelitian dilakukan dengan cara pengumpulan data peledakan dan tingkat getarannya. Kemudian dilakukan analisis scaled distance untuk mengetahui jumlah bahan peledak per delay yang menghasilkan tingkat getaran yang masih memenuhi baku tingkat getaran. Hasil penelitian menunjukkan bahwa jumlah bahan peledak maksimum $19 \mathrm{~kg}$ per delay dan untuk jarak $100 \mathrm{~m}$ masih menghasilkan tingkat getaran yang memenuhi baku tingkat getaran $(3 \mathrm{~mm} / \mathrm{s})$. Jumlah bahan peledak yang cukup aman tiap lubang ledak adalah sekitar $12-15 \mathrm{~kg}$. Usulan perbaikan geometri peledakan dalam penelitian ini adalah pengurangan geometri peledakan dari semula burden 3 meter dan spasi 5 meter menjadi masing-masing 3 meter dan 4 meter dengan tetap mempertahankan berat bahan peledak per lubang $12-15 \mathrm{~kg} / \mathrm{lubang}$. Perbaikan ini diharapkan dapat mempertahankan tingkat getaran yang memenuhi baku tingkat getaran sekaligus memperbaiki kualitas hasil peledakan karena jumlah lubang ledak yang meledak bersamaan tetap sedangkan jarak antar lubang ledak semakin dekat.
\end{abstract}

Kata kunci: Getaran Tanah, Getaran Peledakan, Sistem Delay, Peledakan Batu kapur, PPV

\section{ABSTRACT}

The blasting activity at PT Semen Baturaja (Persero), Tbk., used Dabex explosives and ignited with a non-electric detonator (nonel). The problem arises because the location of the blasting is relatively close to the residential location so that there are often complaints from the community about blasting vibrations. Therefore, the impact of ground vibration is one of the focuses of attention of the mining operation at this company. The research carried out aims to minimize the impact of ground vibrations in order to meet the vibration level standards based on SNI 7571:2010. The research was carried out by collecting data on blasting and vibration levels. Then a scaled distance analysis was carried out to determine the amount of explosives per delay which resulted in a vibration level that still met the vibration level standard. The results showed that the maximum amount of explosives was $19 \mathrm{~kg}$ per delay and for a distance of $100 \mathrm{~m}$ it still produced a vibration level that met the vibration level standards $(3 \mathrm{~mm} / \mathrm{s})$. The amount of explosives that is safe enough per blast hole is around 12-15 kg. The proposed improvement of the blasting geometry in this study is to reduce the blasting geometry from the original 3 meter burden and 5 meter spacing to 3 meters and 4 meters respectively while maintaining the weight of the explosives per hole 12-15 kg / hole. This improvement is expected to maintain a vibration level that meets the vibration level standards while improving the quality of the blasting results because the number of blast holes that explode simultaneously remains constant while the distance between the blast holes is getting closer.

Keywords : Ground Vibration, Blasting Vibration, Delay System, Limestone Blasting, PPV 


\section{PENDAHULUAN}

Kegiatan penambangan batu kapur terdiri dari land clearing, pengupasan top soil dan overburden, peledakan, pemuatan dan pengangkutan batu kapur, penyaliran tambang, dan reklamasi tambang/revegetasi. Kegiatan pemberaian batu kapur dengan peledakan akan menimbulkan dampak getaran tanah [1].

Getaran tanah yang ditimbulkan oleh kegiatan peledakan dapat mengakibatkan berbagai dampak terhadap lingkungan. Pada umumnya Peak Particle Velocity (PPV) atau Peak Particle Acceleration (PPA) digunakan sebagai besaran untuk menentukan tingkat getaran tanah $[2,3,4]$. Kedua parameter ini tergantung pada banyaknya bahan peledak yang meledak dalam waktu yang sama (per delay) dan jarak antara sumber getaran (lokasi peledakan) dengan lokasi pengukuran. Getaran tanah akibat kegiatan peledakan batu kapur perlu dipantau terutama pada saat peledakan dilakukan di lokasi yang dekat dengan pemukiman warga di sekitar tambang. Efek Getaran tanah pada bangunan berdampak terhadap kerusakan struktur bangunan seperti retaknya dinding atau kaca, sedangkan dampak terhadap kemantapan lereng berupa bertambahnya gaya pendorong longsor karena percepatan horizontal (koefisien seismik) $[5,6]$.

SNI 7571 Tahun 2010 tentang baku tingkat getaran peledakan pada kegiatan tambang terbuka terhadap bangunan [7] mengelompokkan bangunan menjadi 5 kelas. Secara umum bangunan di sekitar lokasi penelitian termasuk dalam bangunan kelas 2 dengan PVS maksimum sebesar $3 \mathrm{~mm} / \mathrm{s}$ (Tabel 1)

Tabel 1. Baku tingkat getaran (SNI 7571:2010)

\begin{tabular}{|c|l|c|}
\hline Kelas & \multicolumn{1}{|c|}{ Jenis Bangunan } & $\begin{array}{c}\text { PVS } \\
(\mathrm{mm} / \mathrm{s})\end{array}$ \\
\hline 1 & $\begin{array}{l}\text { Bangunan kuno yang dilindungi undang-undang benda } \\
\text { cagar budaya (Undang-undang No. 6 tahun 1992) }\end{array}$ & 2 \\
\hline 2 & $\begin{array}{l}\text { Bangunan dengan pondasi, pasangan bata dan adukan } \\
\text { semen saja, termasuk bangunan dengan pondasi dari } \\
\text { kayu dan lantainya diberi adukan semen }\end{array}$ & 3 \\
\hline 3 & $\begin{array}{l}\text { Bangunan dengan pondasi, pasangan bata dan adukan } \\
\text { semen diikat dengan slope beton }\end{array}$ & 5 \\
\hline 4 & $\begin{array}{l}\text { Bangunan dengan pondasi, pasangan bata dan adukan } \\
\text { semen slope beton, kolom dan rangka diikat dengan } \\
\text { ring balk }\end{array}$ & $7-20$ \\
\hline 5 & $\begin{array}{l}\text { Bangunan dengan pondasi, pasangan bata dan adukan } \\
\text { semen, slope beton, kolom dan diikat dengan rangka } \\
\text { baja }\end{array}$ & $12-40$ \\
\hline
\end{tabular}

Berdasarkan uraian tersebut, perlu dilakukan penelitian mengenai efek getaran tanah akibat proses peledakan terhadap bangunan di pemukiman sekitar tambang, dengan mengetahui besarnya nilai PPV dan PPA. Selanjutnya mengevaluasi geometri peledakan, penggunaan jenis dan jumlah bahan peledak serta sistem delay yang diterapkan.
Tujuan penelitian ini adalah untuk mereduksi getaran tanah akibat peledakan batu kapur dengan melakukan desain teknis geometri peledakan [8] yang mencakup jumlah bahan peledak dan sistem delay. Diharapkan pada saat area peledakan mendekati pit limit dan area pemukiman, maka getaran tanah PPV dan PPA tidak melebihi nilai ambang batas yang ditetapkan Standar Nasional Indonesia (SNI 7571:2010) [7].

\section{METODE PENELITIAN}

Penelitian dilakukan di tambang batu kapur PT Semen Baturaja (Persero) Tbk yang terletak di Kabupaten Ogan Komering Ulu, Provinsi Sumatera Selatan. Pengukuran getaran dilakukan di lokasi sekitar tambang PT. Semen Baturaja.

Tahapan dalam penelitian ini, meliputi kajian kepustakaan, survey lapangan, pengolahan dan analisis data, serta rekomendasi desain peledakan untuk meminimalisir getaran tanah efek kegiatan peledakan batu kapur. Tahapan awal dilakukan kajian pustaka untuk memperoleh landasan teoritis dan gambaran penelitian. Selanjutnya dilakukan studi lapangan berupa pengumpulan data berupa data primer dan sekunder. Data yang diperoleh diolah dan dianalisis untuk mengetahui dampak dari getaran tanah akibat peledakan batu kapur terhadap bangunan di sekitar tambang. Hasil analisis tersebut akan menjadi acuan dalam mendesain geometri peledakan dan sistem delay yang akan diterapkan selanjutnya.

Teknik pengumpulan data pada penelitian ini adalah sebagai berikut: Tahap kajian kepustakaan terdiri dari kajian literatur, data laporan eksplorasi, dan jurnal yang terkait. Tahap survey lapangan untuk pengumpulan data primer meliputi kegiatan peledakan yaitu pengukuran getaran tanah dan pendataan parameter peledakan (jarak, sistem delay, serta jenis dan jumlah bahan peledak yang digunakan). Disamping data primer, penelitian ini juga didukung data sekunder seperti peta lokasi, data getaran tanah pengukuran sebelumnya dan data penunjang lainnya.

Pengolahan data dilakukan dengan menghitung scaled distance berdasarkan data jumlah bahan peledak dan jarak pengukuran. Selanjutnya dilakukan plot data scaled distance terhadap tingkat getaran (PPV). Hasil plot ini selanjutnya dihitung persamaan regresinya. Persamaan regresi yang dihasilkan digunakan untuk memprediksi PPV pada jarak yang ditetapkan $(100 \mathrm{~m})$ dengan berbagai jumlah isian bahan peledak.

Analisis dilakukan dengan membandingkan tingkat getaran tanah yang didapatkan dari hasil pengukuran terhadap Baku Tingkat Getaran menurut Standar Nasional Indonesia (SNI) Nomor 7571 Tahun 2010. Hasil analisis tersebut akan menjadi dasar dalam 
melakukan redesain peledakan dan penerapan metode kontrol blasting (apabila diperlukan) untuk meminimalisir pengaruh getaran terhadap bangunan yang berada di sekitar tambang batu kapur PT Semen Baturaja (Persero), Tbk.

\section{HASIL DAN PEMBAHASAN}

Geometri Peledakan dan Bahan Peledak

Geometri Peledakan yang diterapkan di PT Semen Baturaja (Persero) Tbk adalah Burden (B) 3 meter dan Spasi (S) $5 \mathrm{~m}$ serta kedalaman (L) $5 \mathrm{~m}$ (Gambar 1). Stemming yang diterapkan berkisar $2-2,5 \mathrm{~m}$ dan subdrilling diperhitungkan $0,3 \mathrm{~m}$. Material yang digunakan sebagai stemming adalah serbuk bor (cuttings).

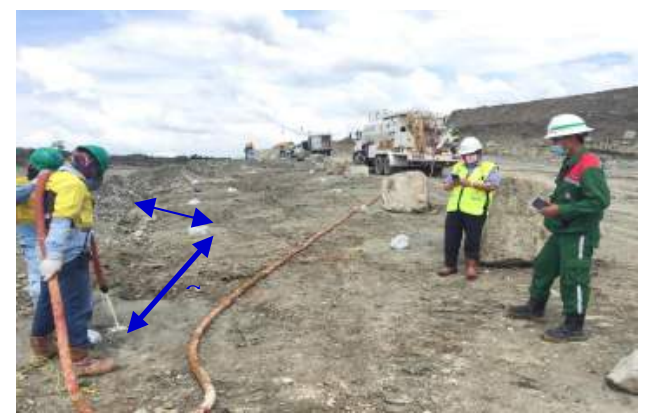

Gambar 1. Geometri peledakan

Bahan peledak yang digunakan adalah Dahana Bulk Explosives (Dabex) dengan komposisi 30\% Anfo dan $70 \%$ Emulsion yang diisikan langsung dari Mobile Mixing Unit/MMU. Berat bahan peledak yang diisikan ke dalam lubang ledak berkisar $12-15 \mathrm{~kg}$ per lubang. Primary Explosives yang digunakan adalah booster dan dirangkaikan dengan in hole delay detonator. Rangkaian peledakan dilakukan dengan non-electric detonator dengan berbagai variasi delay time (Gambar 2). Penyalaan awal dipicu oleh electric detonator yang diledakkan dengan blasting machine.

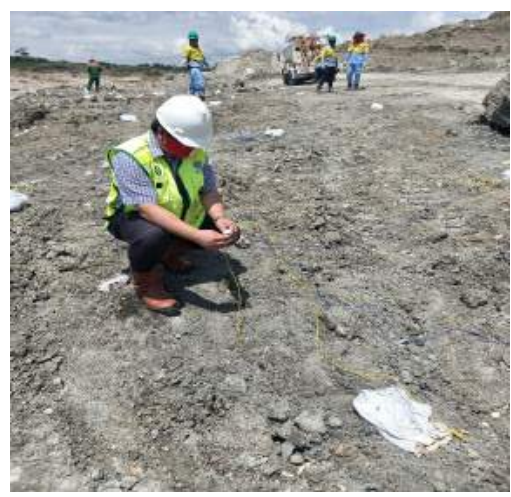

Gambar 2. Rangkaian peledakan
Tingkat Getaran Tanah

Pengukuran getaran tanah yang ditimbulkan dari operasi peledakan dilakukan pada beberapa lokasi peledakan (Gambar 3), lokasi titik pengukuran getaran dan jumlah bahan peledak yang bervariasi. Hasil dari 34 kali pengamatan menunjukkan tingkat getaran tanah (PVS) bervariasi dari 0,356 hingga $3,317 \mathrm{~mm} / \mathrm{s}$ (Tabel 2).

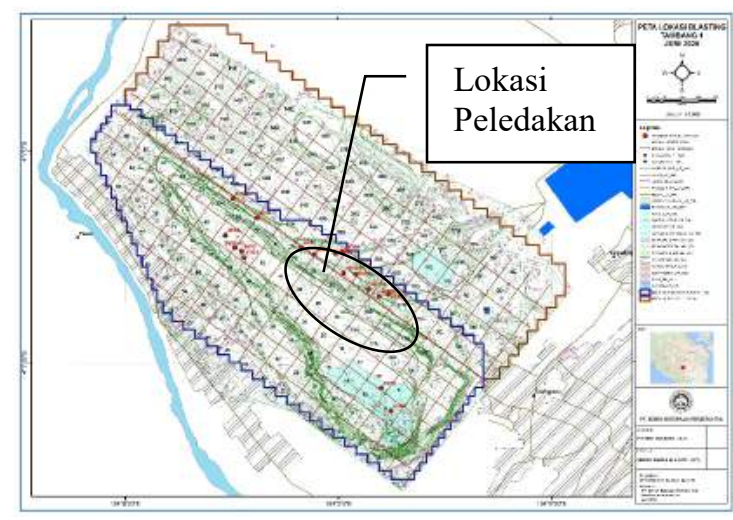

Gambar 3. Peta lokasi peledakan

Tabel 2. Getaran tanah akibat peledakan

\begin{tabular}{|c|c|c|c|c|}
\hline $\mathrm{NO}$ & $\begin{array}{l}\text { Lokasi } \\
\text { Peledakan }\end{array}$ & $\begin{array}{c}\text { Jarak } \\
(\mathrm{m})\end{array}$ & $\begin{array}{c}\text { Bahan } \\
\text { Peledak } \\
\text { Per Delay } \\
(\mathrm{KG})\end{array}$ & $\begin{array}{c}\text { PVS } \\
(\mathrm{mm} / \mathrm{s})\end{array}$ \\
\hline 1 & Sump, 28/62 & 190 & 9,8 & 2,421 \\
\hline 2 & Sump, 28/62 & 430 & 9,8 & 0,578 \\
\hline 3 & Sump, 28/62 & 320 & 9,8 & 0,512 \\
\hline 4 & $40 / 27 \mathrm{~A}, 49 / 39$ & 270 & 16,6 & 2,370 \\
\hline 5 & 40/27A, 49/39 & 560 & 16,6 & 0,663 \\
\hline 6 & $40 / 27 \mathrm{~A}, 49 / 39$ & 750 & 16,6 & 0,472 \\
\hline 7 & $12 / 10,28 / 62$ & 270 & 10,0 & 1,428 \\
\hline 8 & $12 / 10,28 / 62$ & 320 & 10,0 & 0,756 \\
\hline 9 & $12 / 10,28 / 62$ & 580 & 10,0 & 0,550 \\
\hline 10 & $49 / 40-52$ & 190 & 15,8 & 1,981 \\
\hline 11 & $49 / 40-52$ & 500 & 15,8 & 0,361 \\
\hline 12 & $52 / 28 \mathrm{~A}, 52 / 52$ & 660 & 23,1 & 0,704 \\
\hline 13 & $52 / 28 \mathrm{~A}, 52 / 52$ & 410 & 23,1 & 0,765 \\
\hline 14 & $24 / 53$ & 240 & 13,2 & 1,140 \\
\hline 15 & $24 / 53$ & 315 & 13,2 & 0,567 \\
\hline 16 & sump, $12 / 10$ & 250 & 13,8 & 1,130 \\
\hline 17 & sump, $12 / 10$ & 400 & 13,8 & 0,434 \\
\hline 18 & $49 / 28 \mathrm{~A}$ & 250 & 11,6 & 0,930 \\
\hline 19 & $49 / 28 \mathrm{~A}$ & 650 & 11,6 & 0,488 \\
\hline 20 & $49 / 18 \mathrm{c}$ & 150 & 15,6 & 1,397 \\
\hline 21 & $12 / 10,24 / 53-62$ & 580 & 8,2 & 1,380 \\
\hline 22 & $12 / 10,24 / 53-62$ & 330 & 8,2 & 0,840 \\
\hline 23 & $42 / 18 \mathrm{C}$ & 220 & 8,5 & 2,263 \\
\hline 24 & $40 / 40 \mathrm{~A}, 42 / 40 \mathrm{~A}$ & 210 & 11,4 & 1,763 \\
\hline 25 & $40 / 40 \mathrm{~A}, 42 / 40 \mathrm{~A}$ & 500 & 11,4 & 0,721 \\
\hline 26 & $24 / 62$ & 170 & 6,8 & 3,317 \\
\hline 27 & $24 / 62$ & 300 & 6,8 & 0,686 \\
\hline 28 & $12 / 10$ & 220 & 10,1 & 1,397 \\
\hline 29 & $12 / 10$ & 400 & 10,1 & 0,356 \\
\hline 30 & $12 / 10,50 / 39 \mathrm{~A}$ & 580 & 10,6 & 0,983 \\
\hline 31 & $31 / 53$ & 180 & 9,6 & 3,022 \\
\hline 32 & $31 / 53$ & 315 & 9,6 & 1,441 \\
\hline 33 & sump,60/64A & 270 & 23,1 & 0,711 \\
\hline 34 & sump,60/64A & 250 & 23,1 & 0,720 \\
\hline
\end{tabular}


Analisis Scaled Distance terhadap Peak Pacticle Velocity $(P P V)$

Analisis Scale Distance dilakukan terhadap data tingkat getaran yang ditimbulkan operasi peledakan. Data berat bahan peledak per delay dan data jarak pengukur dihitung untuk mendapatkan data scaled distance (SD) $[9,10]$. Selanjutnya scaled distance ini digunakan sebagai viariabel terikat dan data tingkat getaran (PPV) sebagai variabel bebas.

Data SD terhadap PPV di plot pada skala logaritmik dan selanjutnya dihitung persamaan regresi antara kedua data tersebut. Hasil perhitungan memberikan persamaan umum PPV $=37,927(\mathrm{SD})^{-0,811}$ (Gambar 4). Hasil penelitian menunjukkan bahwa hubungan PPV dengan SD adalah berbanding terbalik dimana semakin besar scaled distance maka PPV yang dihasilkan semakin kecil. Hal ini sesuai dengan teori dasar semakin jauh dari sumber peledakan maka tingkat getaran akan semakin kecil.

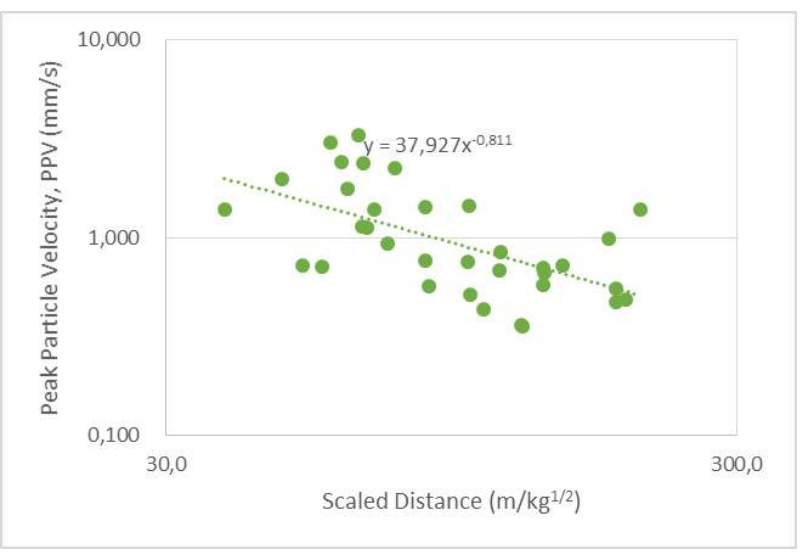

Gambar 4. Peak Particle Velocity Vs Scaled Distance

Persamaan umum PPV yang dihasilkan digunakan untuk memperkirakan besarnya PPV yang akan dihasilkan berdasarkan jarak tertentu dari lokasi peledakan. Jarak yang ditetapkan dalam penelitian ini adalah $100 \mathrm{~m}$ dari lokasi peledakan. Penetapan jarak $100 \mathrm{~m}$ ini, selain mempertimbangkan getaran peledakan juga atas pertimbangan keamanan dari batuan terbang (fly rock) dari peledakan dan suara peledakan.

Perkiraan tingkat getaran pada jarak $100 \mathrm{~m}$ dari lokasi peledakan menunjukkan bahwa PPV akan mencapai batas baku tingkat getaran bila berat bahan peledak per delay peledakan sebesar $19 \mathrm{~kg}$ atau lebih (Gambar 5).

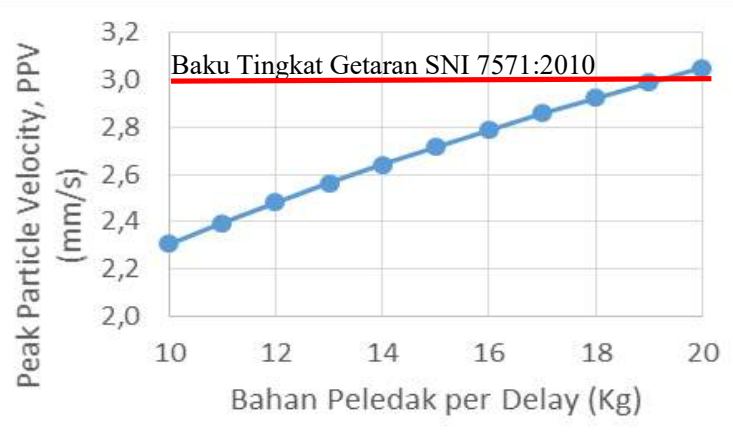

Gambar 5. Perkiraan PPV berdasarkan berat bahan peledakan (pada Jarak $100 \mathrm{~m}$ )

Pengaturan Geometri Peledakan

Banyaknya keluhan dari masyarakat sekitar terkait dengan getaran peledakan di lokasi tambang membuat PT Semen Baturaja lebih mengedepankan minimalisir konflik dengan masyarakat. Akhir-akhir ini PT Batubara hanya memuat bahan peledak berkisar $12-15 \mathrm{~kg} / \mathrm{lubang}$ ledak. Hal ini berarti bahan peledak dalam satu lubang ledak masih memenuhi perkiraan PPV. Hal yang penting diperhatikan adalah memastikan bahwa tidak ada lubang ledak yang meledak bersamaan. Oleh karena itu diperlukan pengaturan delay yang baik.

Pengaturan delay peledakan pada prinsipnya akan memberikan jeda waktu tertentu antara meledaknya lubang ledak yang satu dengan lubang ledak lainnya. Kombinasi dua nomor delay untuk nonel yang digunakan dengan selang seling cukup efektif untuk mengatur agar tidak terjadi dua lubang meledak bersamaan. Penggunaan software akan sangat membantu perencanaan penyalaan. Apabila belum memiliki software juga dapat dianalisis dengan sederhana berdasarkan penjumlahan delay time masing-masing lubang ledak.

Dampak dari dibatasinya isian bahan peledak adalah banyaknya bongkah yang terbentuk dari hasil peledakan. Selama ini bongkah-bongkah yang terbentuk diledakkan kembali dengan secondary blasting.

Sebagai upaya untuk mengurangi bongkah yang terjadi diusulkan mengubah geometri peledakan menjadi lebih dekat yaitu burden $3 \mathrm{~m}$ dan spasi yang semula 5 meter diubah menjadi 4 meter. Dengan perubahan ini maka jarak antar lubang ledak semakin dekat sedangkan jumlah bahan peledak yang meledak dalam satu waktu tetap. Dengan demikian akan tetap dapat meminimalisir dampak getaran dan sekaligus mengurangi terbentuknya bongkahan hasil peledakan. 


\section{KESIMPULAN}

Peledakan batu kapur di PT Semen Baturaja (Persero) Tbk 1 menerapkan sistem peledakan non-electric blasting dengan bahan peledak Dabex. Tingkat getaran tanah menunjukkan masih ada beberapa data pengukuran yang melebih baku tingkat getaran (PPV maks $3 \mathrm{~mm} / \mathrm{s}$ ). Hasil simulasi PPV menunjukkan pada jarak $100 \mathrm{~m}$ jumlah bahan peledak maksimum per delay adalah $19 \mathrm{~kg}$ untuk dapat memenuhi baku tingkat getaran berdasarkan SNI 7571 Tahun 2010. Dalam rangka mengurangi bongkah, spasi dapat diubah dari 5 meter menjadi 4 meter dengan tetap mempertahankan berat bahan peledak per delay.

\section{UCAPAN TERIMA KASIH}

Penulis mengucapkan terima kasih kepada Universitas Sriwijaya atas pendanaan penelitian SATEKS. Selain itu juga disampaikan ucapan terima kasih untuk PT Semen Baturaja atas kesempatan kunjungan lapangan untuk penelitian dan data yang telah diberikan.

\section{DAFTAR PUSTAKA}

[1] Gokhale, B.V., (2011). Rotary Drilling \& Blasting In large Surface Mine. Tayloy \& Friend Group: London.

[2] Fitri, D. A., Toha, M. T., dan Bochori, (2014). Evaluasi Perimeter Blasting Terhadap Tingkat Getaran Tanah (Ground Vibration) Pada Pre Bench Pit Air Laya PT. Bukit Asam (Persero), Tbk. Jurnal Ilmu Teknik Vol. 2, No. 5. Universitas Sriwijaya.

[3] Ghadafi, M.A., Toha, M.T., Setiabudidaya, D. (2017). Effect of Ground Vibration to Slope Stability, Case Study Landslide on The Mouth of Railway Tunnel, Gunung Gajah Village, Lahat District. Sriwijaya Journal of Environemnt Vol. 2 No. 3, November 2017.

[4] Evelvi, B. dan Arpaz, E.. (2010), Evaluation of Parameters Affected on the Blast Induced Ground Vibration (BIGV) by Using Relation Diagram Method (RDM). Ročník 15. (4): 261268.

[5] Noviansyah, M. R., Toha, M. T., Bochori. (2017). Rancangan Sistem Waktu Tunda Peledakan Nonel Untuk Mengurangi Efek Getaran Tanah Terhadap Fasilitas Tambang. Jurnal Pertambangan Vol. 1 No. 3, Mei 2017

[6] Rizki M, Toha M.T., and Soedarmono D, (2014). Kajian pengaruh tingkat getaran tanah (Ground Vibration Level) pada Operasi Peledakan Interburden B2-C Tambang Batubara Air Laya. Jurnal Ilmu Teknik. 2(1): 25-33

[7] SNI 7571. (2010). Baku Tingkat Getaran Peledakan Pada Kegiatan Tambang Terbuka Terhadap
Bangunan. Bandung: Badan Standarisasi Nasional.

[8] Toha, M. T., Bochori, and Waluyo, (2017), Blasting Design Without Subdrilling on Jointed Limestone to Optimize Fragmentation. International Journal on Advanced Science Engineering Information Technology Vol. 7 No. 5 ISSN : 2088-5334.

[9] Fuad Warhana, (2020), Kajian Jarak Aman Peledakan Terhadap Cadangan Tertambang Di Tambang Baturaja I PT Semen Baturaja (Persero) Tbk, Tesis, Fakultas Teknik : Universitas Sriwijaya.

[10] Cahyadi, R., Toha, T., dan Komar, S.. (2017). Analisis Korelasi Scaled Distance terhadap Getaran Tanah pada Operasi Peledakan Batu Kapur PT Semen Baturaja (Persero). Jurnal Teknik Patra Akademika. 8(2): 26-38 